\title{
New structurally interesting cyclopropane derivatives. A world of wonders and surprises*
}

\author{
Armin de Meijere ${ }^{1, \ddagger}$, Sergei I. Kozhushkov ${ }^{1}$, Andrey A. Fokin ${ }^{2}$, \\ Ingo Emme ${ }^{1}$, Stefan Redlich ${ }^{1}$, and Peter R. Schreiner ${ }^{2}$ \\ ${ }^{1}$ Institut für Organische Chemie der Georg-August-Universtität Göttingen, \\ Tammannstrasse 2,D-37077 Göttingen, Germany; ${ }^{2}$ Institut für Organische Chemie, \\ Justus-Liebig-Universität Giessen, Heinrich-Buff-Ring 58, D-35392 Giessen, \\ Germany
}

\begin{abstract}
The structurally intriguing [4]- and [5]triangulanes have been prepared in enantiomerically pure form. Their surprisingly high specific rotations are well reproduced by DFT/SCI computations and stem from the fact that these hydrocarbons essentially are $\sigma$-helicenes (i.e., rigidly held helical arrangements of $\sigma$-bonds). Some light is shed on the properties of radical cations derived from [3]- and [4]rotanes. While the former adopts $C_{\mathrm{s}}$ or $C_{2 \mathrm{v}}$ symmetry, the latter retains the $D_{4 \mathrm{~h}}$ symmetry of the neutral hydrocarbon, according to highlevel computations. Experimental and computational evidence is also presented that the antiaromatic cyclopentadienyl cation is stabilized as a singlet ground state by five cyclopropyl substituents. Yet, the three cyclopropyl groups in tricyclopropylamine do not favor the formation of its radical cation, because they are not in the proper orientation. When this amine radical cation is generated by cobalt $\gamma$-irradiation in a Freon matrix, evidence for a significant conformational change is obtained by EPR spectroscopy. Finally, the conformational dynamics of the newly prepared crowded molecules tetracyclopropyl- and tetraisopropylmethane are discussed.
\end{abstract}

\section{INTRODUCTION}

Cyclopropane chemistry has long gained economical importance due to a number of best-selling pharmaceuticals containing cyclopropyl groups. Yet, new cyclopropane derivatives still come along with a flavor of curiosity, just as it was about 120 years ago, when William Henry Perkin synthesized the first cyclopropane derivative [1]. It was sheer curiosity that led him to try out what seemed to be impossible for others, who had advised him not to waste his time on such an endeavor [2]. The frontiers of cyclopropane chemistry have been pushed forward by a long distance since 1884, and modern synthetic methodology has made it possible to deal with the strangest looking molecular aggregates of many cyclopropyl groups that even nowadays may appear impossible or a waste of time to deal with for some practitioners of the chemical sciences. However, cyclopropane chemistry is still intriguing and always coming along with a bonding theoretical aspect (Fig. 1).

\footnotetext{
*Plenary lecture presented at the $16^{\text {th }}$ International Conference on Physical Organic Chemistry (ICPOC-16): Structure and Mechanism in Organic Chemistry, San Diego, California, USA, 4-9 August 2002. Other presentations are published in this issue, pp. 541-630.

¥Corresponding author: E-mail: Armin.deMeijere@chemie.uni-goettingen.de
} 


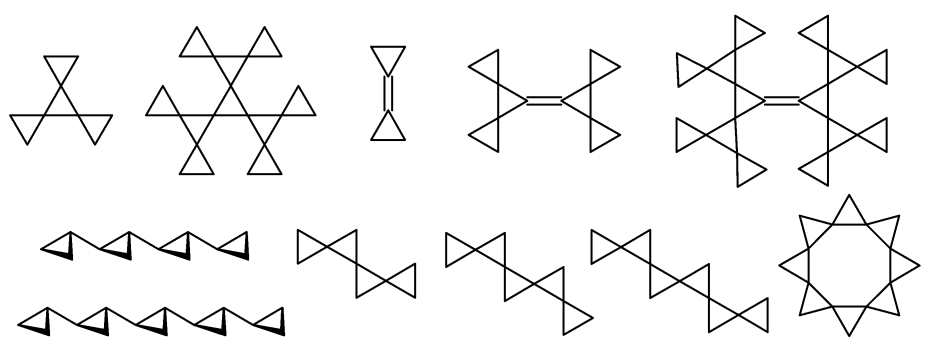

Fig. 1 Some molecular aggregates of cyclopropyl groups appealing to curiosity and aesthetics.

\section{THE FIRST ENANTIOMETRICALLY PURE [n]TRIANGULANES}

Even nature makes compounds containing oligocyclopropyl groups with four, and even with five consecutive cyclopropane rings attached to each other [3]. The family of spiro-linked cyclopropane aggregates, the so-called [n]triangulanes [4], consists of linear, branched, and cyclic arrays [5]. Among them, the linear triangulanes with more than three spiro-linked cyclopropane units display an interesting stereochemical phenomenon in that they are chiral, but with stereogenic centers that have four different alkyl substituents only [6]. This stimulated us to prepare the first $[n]$ triangulanes in enantiomerically pure form and investigate their properties (Scheme 1) [7,8].

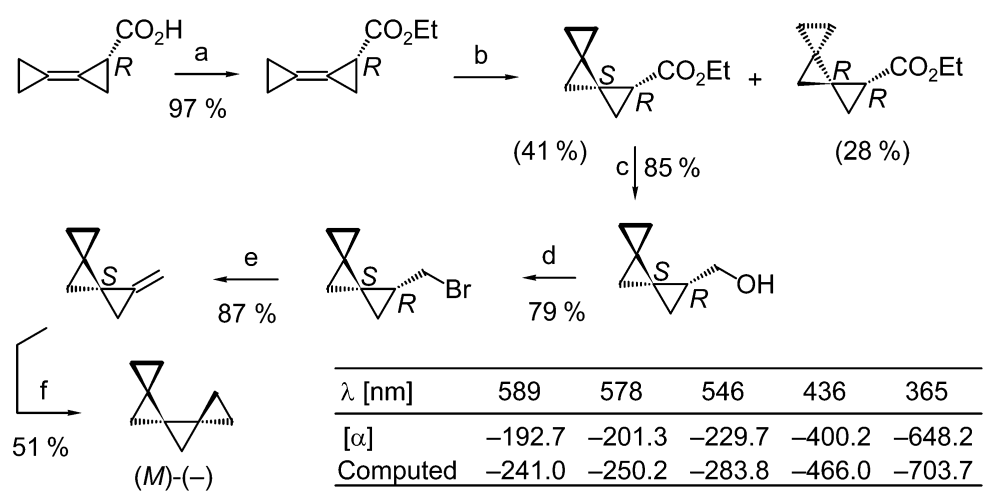

Scheme 1 First synthesis of enantiomerically pure $(M)-(-)-[4]$ triangulane and a comparison of its measured and DFT/SCI-computed specific rotations [7]. (a) $\mathrm{BF}_{3} \cdot \mathrm{Et}_{2} \mathrm{O}$, EtOH, $78^{\circ} \mathrm{C}, 2 \mathrm{~h}$; (b) $\mathrm{CH}_{2} \mathrm{I}_{2}$, Zn, DME, ultrasound, $80^{\circ} \mathrm{C}$, $2 \mathrm{~h}$; (c) $\mathrm{LiAlH}_{4}, \mathrm{Et}_{2} \mathrm{O}$; (d) $\mathrm{Ph}_{3} \mathrm{P} \cdot \mathrm{Br}_{2}, \mathrm{Py}, \mathrm{CH}_{2} \mathrm{Cl}_{2},-10{ }^{\circ} \mathrm{C}, 1.5 \mathrm{~h}$, then $20^{\circ} \mathrm{C}, 7 \mathrm{~h}$; (e) $t \mathrm{BuOK}, \mathrm{DMSO}, 20{ }^{\circ} \mathrm{C}, 14 \mathrm{~h}$; (f) $\mathrm{CH}_{2} \mathrm{~N}_{2}, \mathrm{Pd}(\mathrm{OAc})_{2}, \mathrm{Et}_{2} \mathrm{O},-5{ }^{\circ} \mathrm{C}$.

To start with, bicyclopropylidenecarboxylic acid was deracemized by crystallization of its dehydroabietylamine salt. The absolute configuration of one enantiomer was established as being $R$ by an $\mathrm{X}$-ray crystal structure analysis of its $\alpha$-phenylethylamide. Esterification, cyclopropanation, diastereomer separation at the stage of the [3]triangulanecarboxylate, reduction, conversion to the bromide, dehydrobromination, and cyclopropanation led to enantiomerically pure [4]triangulane (ee, $\geq 98 \%$ according to gas chromatography on a chiral phase column) (Scheme 1). The most striking feature of this hydrocarbon, which has no chromophore and is transparent in the UV region down to $200 \mathrm{~nm}$, is its specific rotation of $192.7^{\circ}$ at $589 \mathrm{~nm}$. The rotation increases significantly at shorter wavelengths, indicating a quite remarkable amplitude of its Cotton effect, which must lie in the vacuum UV region. These high-specific rotations at all measured wavelengths are very well reproduced by density functional theory computations, applying a full valence space single-excitation configuration interaction (SCI) treatment. This enhances the confidence in the interpretation that the high-specific rotations are due to the rigid helical arrangements of $\sigma$-bonds in these triangulanes, as depicted in Fig. 2. 


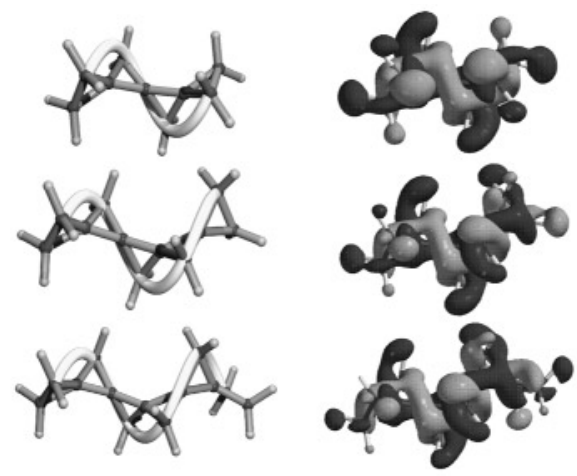

Fig. 2 Helicity of $(M)$-[4]-, $(M)$-[5]-, and $(M)$-[6]triangulane. Left: A helical ribbon continously connecting the methylene groups. Right: Lowest unoccupied molecular orbitals (LUMOs) [7,8].

A line connecting the methylene groups of the inner spiropentane moieties with one each of the outer rings resembles a mechanical model of the helicity of [4]-, [5]-, and [6]triangulane. The lowest unoccupied molecular orbitals express the same feature. The two lobes are essentially intertwined helices. The calculations predicted an almost twofold value for the specific rotation of [5]triangulane, and this intrigued us to test it experimentally.

Fortunately, three of the four diastereomeric ethyl [4]triangulanecarboxylates obtained by rhodium-catalyzed cyclopropanation with ethyl diazoacetate of either one of the enantiomerically pure 1-methylene[3]triangulanes could be distilled off the remaining one through a high-performance concentric tube column, and the residue in the distillation flask proved-by X-ray crystallography-to be one of two diastereomers that could be used to proceed further (Scheme 2) [8].

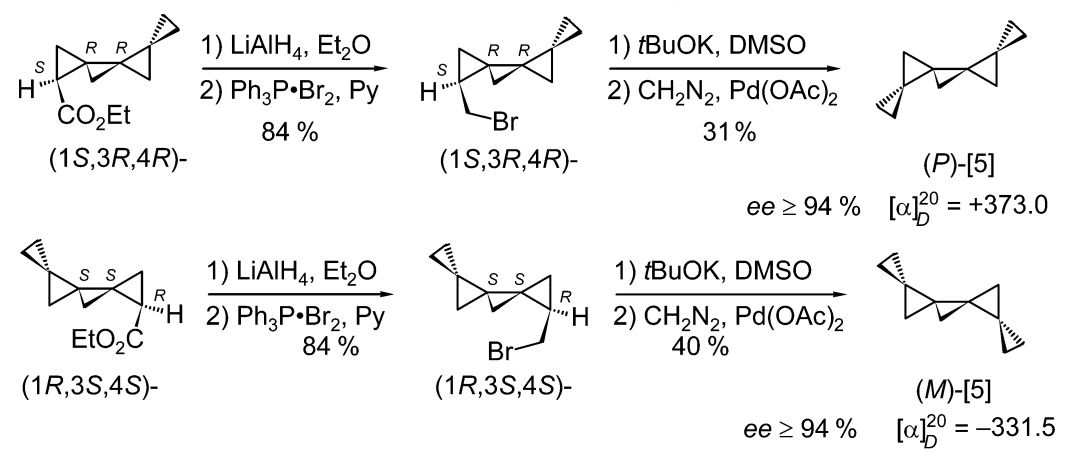

Scheme 2 Preparation and properties of $(M)$-[5]- and $(P)$-[5]triangulane [8].

Further elaboration according to the same sequence of transformations as applied toward $(M)$-[4]triangulane, i.e., reduction of the ester to an alcohol, conversion of the latter to a bromide, dehydrobromination, and cyclopropanation, gave the $(P)$ - and $(M)$-[5]triangulane, respectively. The specific rotation for the $(P)$-enantiomer, which was proved to have an enantiomeric excess of $\geq 94 \%$ by gas chromatography on a chiral column, turned out to be $+373^{\circ}$, indeed almost twice that for the corresponding [4]triangulane. The crystal structures of the enantiomerically pure $(P)$-enantiomer and of the racemic [5]triangulane were both determined by X-ray diffraction. While the molecular structures were-of course-identical, the crystal packing for the enantiomerically pure and the racemic compound were found to be significantly different [8]. Although the enantiomeric purity for the $(M)$-enantiomer was of the same order as that for the $(P)$-enantiomer, the specific rotation was about $11 \%$ 
smaller. This was found to be due to a lower chemical purity of this enantiomer, and thus the value measured for the $(P)$-enantiomer is the more reliable one.

In view of all of their features, one may justifiably consider these triangulanes as being the $\sigma$-analogs of the aromatic helicenes and may therefore call them $\sigma$-helicenes, while the aromatic congeners should further be called $\pi$-helicenes. It would undoubtedly be interesting to prepare the next higher analogs of these [4]- and [5]- $\sigma$-helicenes in enantiomerically pure form and test their properties, but in view of the increasing number of possible stereoisomers-[6]triangulane can exist in three enantiomeric pairs, only one of which is a pair of $\sigma$-helices [9] - the linear synthesis as exercised for the enantiomerically pure [4]- and [5]triangulane, would be far too tedious and cumbersome. Therefore, a more convergent approach to higher analogs in the series is being developed [10].

\section{RADICAL CATIONS OF [ $n]$ ROTANES}

The $[n]$ rotanes are also a class of hydrocarbons that consist of spiro-linked cyclopropane units only, but with a common $n$-membered ring in the middle [11]. A recent computational study revealed that [3] rotane — which at the same time is a branched [4]triangulane—-should have a reasonably low oxidation potential so that oxidation could be brought about by chemical means. A DFT computational study revealed that adiabatic single electron transfer requires $196 \mathrm{kcal} / \mathrm{mol}$ [12] and leads to a radical cation that exists in two energetically very similar states (Fig. 3). The energetically slightly higher one (1.9 $\mathrm{kcal} / \mathrm{mol}$ ) has $C_{2 \mathrm{v}}$ symmetry and a drastically elongated bond in the central ring, the other one with $C_{\mathrm{s}}$ symmetry $(0.0 \mathrm{kcal} / \mathrm{mol})$ has one of the proximal bonds of the outer cyclopropane rings even more significantly elongated [13].
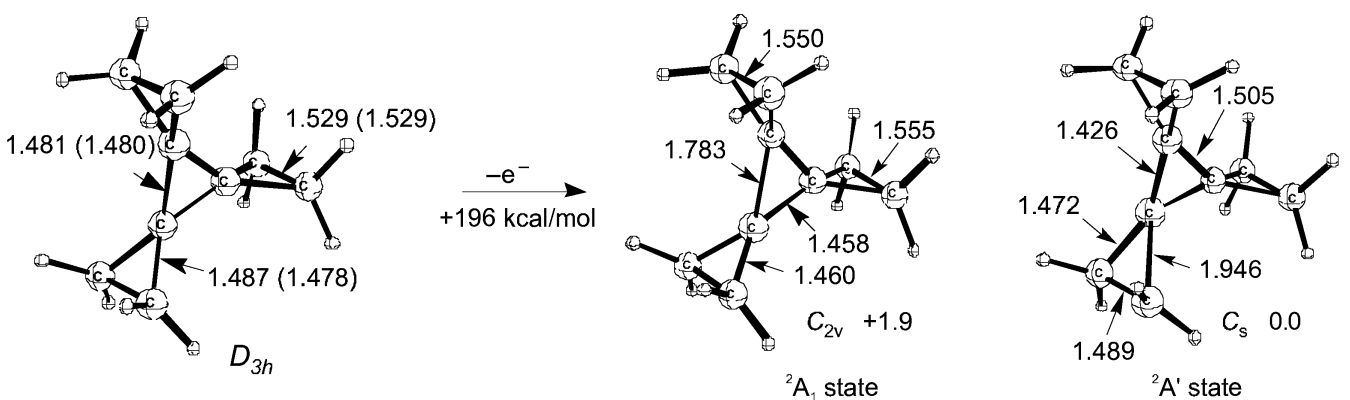

Fig. 3 [3]Rotane and its radical cation according to DFT calculations at the B3LYP/6-311+G**//B3LYP/6-31G* level. Bond lengths in $\AA$. Experimental data (X-ray) for the neutral hydrocarbon in parentheses.

The chemical behavior of [3] rotane upon oxidation with cerium ammonium nitrate resembles exactly that property of the radical cation in that it traps the solvent acetonitrile and the nitrate anion with opening of one of these proximal bonds in one of the external cyclopropane rings (Scheme 3) [14].

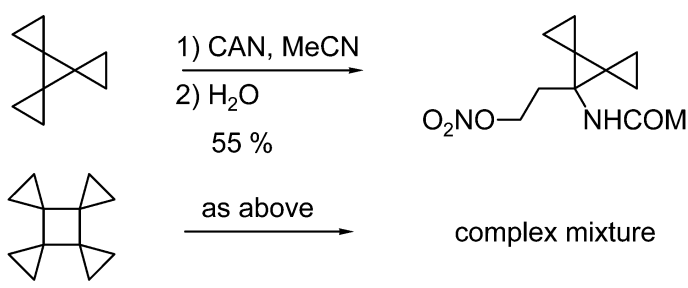

Scheme 3 Selective oxidative bond breaking in [3]rotane. $\mathrm{CAN}=\left(\mathrm{NH}_{4}\right)_{2} \mathrm{Ce}\left(\mathrm{NO}_{3}\right)_{6}$. 
Oxidation of [4]rotane under the same conditions gave a complex mixture from which no identifiable product could be isolated. This may be taken to indicate that the computational prediction concerning the radical cation of [4]rotane to retain the $D_{4 \mathrm{~h}}$ symmetry of the neutral hydrocarbon, with no drastic bond elongations as seen in the [3] rotane radical cation, ought to be correct. With $177 \mathrm{kcal} / \mathrm{mol}$, the adiabatic ionization energy is $19 \mathrm{kcal} / \mathrm{mol}$ lower than that of [3] rotane [12]. This feature derives from the fact that [4]rotane does not have degenerate highest occupied molecular orbitals (HOMOs), and thus Jahn-Teller distortion cannot occur (Fig. 4).

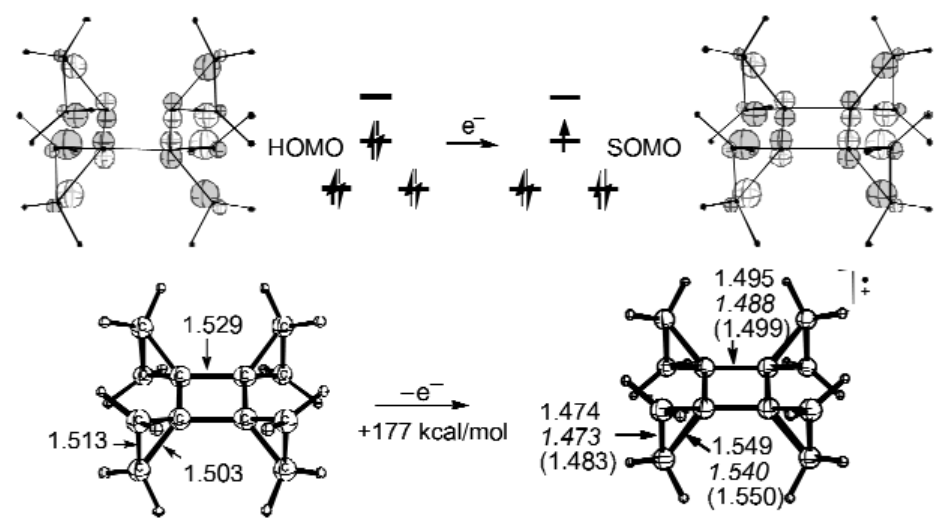

Fig. 4 [4]Rotane and its radical cation. HOMO and geometry of [4]rotane as well as SOMO (semi-occupied molecular orbital) and geometry of its radical cation according to B3LYP/6-31G*, MP2/6-31G* (italics), and CCSD/cc-pVDZ (in parentheses) calculations. All bond lengths in $\AA$.

Even at a reasonably high level of theory (CCSD/cc-pVDZ), the radical cation of [4]rotane is calculated to have significantly shortened bonds in the central four-membered ring and slightly elongated proximal as well as slightly shortened distal bonds in the spirocyclopropane units. Thus, there is no obvious preferred point of attack of a nucleophile that would eventually lead to a preferred ring-opening trapping product.

\section{THE QUEST FOR PENTACYCLOPROPYLCYCLOPENTADIENYL CATION}

Cyclopropyl substituents are known to more efficiently stabilize a carbocation than even a phenyl or a vinyl group [15]. The tricyclopropylcyclopropenylium cation, therefore, is the most stable in the series of trialkyl-substituted cyclopropenylium cations, only heteroatom substituents exceed the stabilizing power of three cyclopropyl groups [16]. The $\mathrm{pK}_{\mathrm{R}+}$ value of tricyclopropylcyclopropenylium cation (9.47) [16] exceeds that of the triisopropyl derivative (6.4) by three orders of magnitude [16a]. Three and four cyclopropyl groups have been shown to stabilize the cycloheptatrienyl cation tremendously, raising the $\mathrm{pK}_{\mathrm{R}+}$ from 4.7 to 8.7 and even 9.1, respectively [17]. It is remarkable that the fourth cyclopropyl group, although necessarily adjacent to one of the other three, still enhances the stability significantly. One may therefore extrapolate that the unknown heptacyclopropylcycloheptatrienyl cation would be even more stable.

With these stabilizing effects on cationic aromatic systems in mind, one would be inclined to predict that five cyclopropyl groups attached to the antiaromatic cyclopentadienyl cation might be able to let the system overcome the instability caused by its antiaromaticity. The parent cyclopentadienyl cation [18], its pentachloro derivative [19], and the pentaisopropyl-substituted compound [20], have all been generated at low temperatures ( 78 and $115 \mathrm{~K}$ ), respectively, and shown by electron spin resonance (ESR) spectroscopy to exist as triplet species [21]. The singlet-triplet gap is significantly lowered for 
the pentaarylcyclopentadienyl cations, especially for those with donor-substitued aryl groups, so that the singlet species become detectable at $-40{ }^{\circ} \mathrm{C}[22]$.

Although only two of the five cyclopropyl substituents around the cyclopentadienyl cation core adopt the proper orientation for their acting as electron donors, as predicted by a simple AM1 calculation, the two exert a unique stabilizing effect according to DFT and Hartree-Fock computations at the BLYP/3-21G and HF/3-21G levels of theory (Fig. 5) [23].

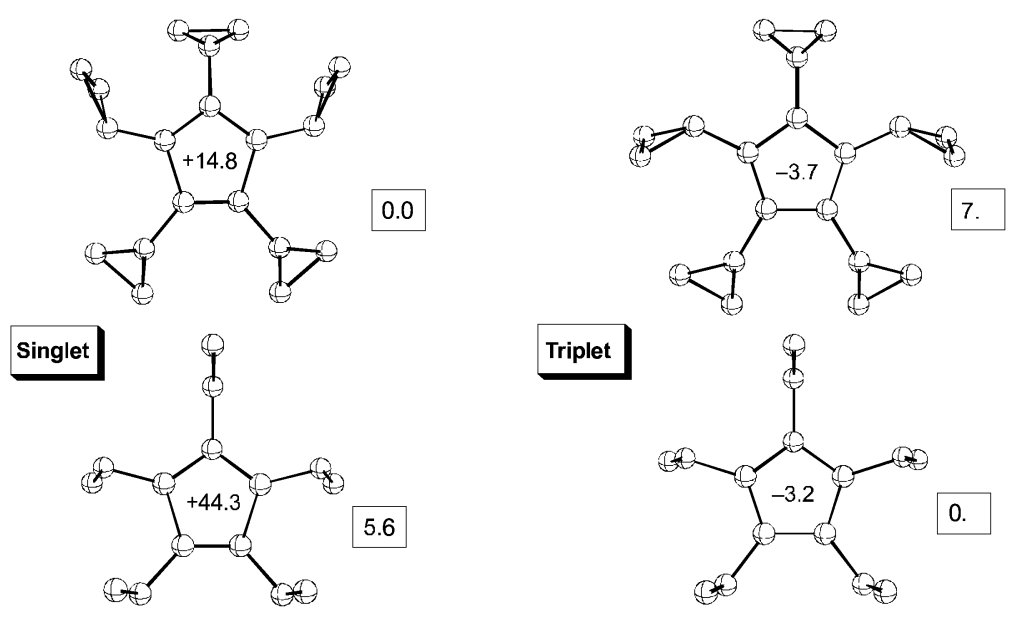

Fig. 5 The effect of five cyclopropyl as compared to five ethyl groups on a cyclopentadienyl cation [23]. Energy single points (in frames) in $\mathrm{kcal} / \mathrm{mol}$ according to $\mathrm{BLYP} / 3-21 \mathrm{G}$; optimization and NICS values in the centers of the rings according to $\mathrm{HF} / 3-21 \mathrm{G}$. Computations at a higher level of theory are in progress.

As opposed to the pentaethylcyclopentadienyl cation, for which the triplet state is $5.6 \mathrm{kcal} / \mathrm{mol}$ lower than the singlet state, the singlet of pentacyclopropylcyclopentadienyl cation is more stable than the triplet state by $7.8 \mathrm{kcal} / \mathrm{mol}$ (Fig. 5). The nucleus-independent chemical shift (NICS) values for both systems indicate that five cyclopropyl compared to five ethyl groups lower the antiaromatic character of the system quite significantly, going from a value of +44.3 in the center of the pentaethyl-substituted to +14.8 in the center of the pentacyclopropyl-substituted system [24].

With the proper choice of conditions, the synthesis of pentacyclopropylcyclopentadiene turned out to be surprisingly simple. Readily available dicyclopropylacetylene [25] can be converted by hydromagnesiation, adopting a protocol of Sato et al. [26], to 1,2-dicyclopropylethenylmagnesium bromide. This organometallic, when added to methylcyclopropanecarboxylate, only yielded the 1,4-adduct of the initially formed cyclopropyl (1,2-dicyclopropylethenyl) ketone. However, when this Grignard reagent is first transmetallated with cerium(III) chloride to the corresponding ethenylcerium species [27], clean twofold 1,2-addition of the organometallic to the carbonyl group of methyl cyclopropanecarboxylate occurs, and pentacyclopropylcyclopentadiene is isolated in $64 \%$ yield after workup with aqueous acetic acid (6:1) [28].

Just like other cyclopentadienes, this new derivative can be deprotonated by treatment with methyllithium in ether, and the lithium cyclopentadienide can be treated with $\mathrm{N}$-chlorosuccinimide to provide pentacyclopropylcyclopentadienyl chloride in $95 \%$ yield (Scheme 4 ). The latter appears to be an appropriate precursor to the corresponding cyclopentadienyl cation. The new cyclopentadienide could also be trapped with iron dichloride in tetrahydrofuran to yield decacyclopropylferrocene. As a first probe into the cyclopropyl group donating ability in these systems, the oxidation potential of the new ferrocene as well as the octacyclopropyl derivative, prepared analogously from tetracyclopropylcyclopentadiene, were measured and compared to the known values for ferrocene itself and its decamethyl derivative (Fig. 6) [28]. 

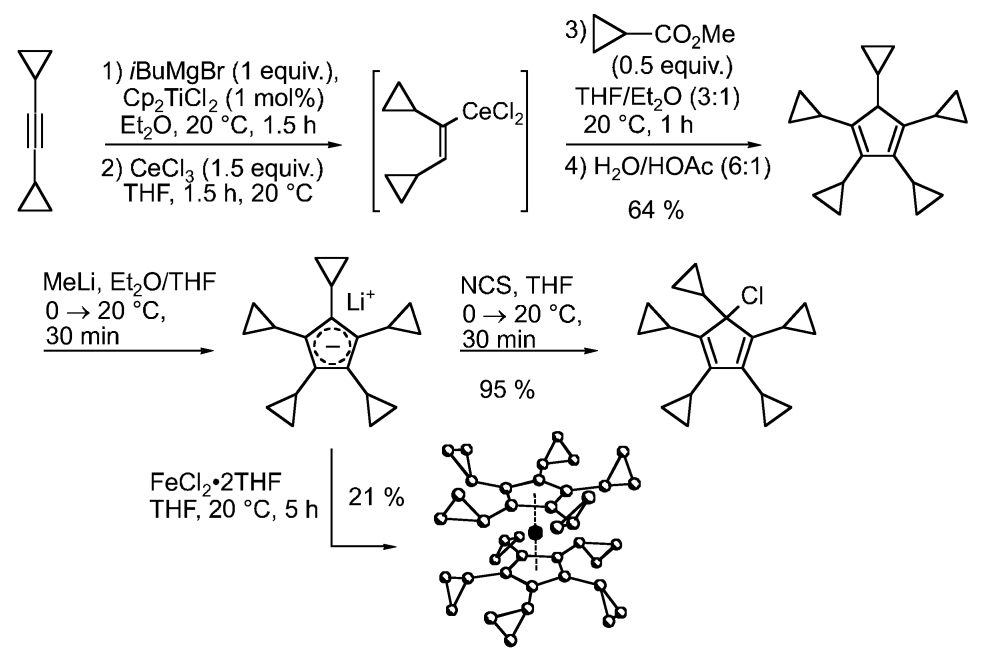

Scheme 4 Synthesis and further transformations of pentacyclopropylcyclopentadiene.

$$
\begin{aligned}
& \mathrm{Cp}_{2} \mathrm{Fe} \quad\left(\mathrm{Me}_{5} \mathrm{Cp}\right)_{2} \mathrm{Fe} \quad\left(\mathrm{CPr}_{4} \mathrm{CpH}\right)_{2} \mathrm{Fe} \quad\left(\mathrm{CPr}_{5} \mathrm{Cp}\right)_{2} \mathrm{Fe} \\
& \begin{array}{llll}
E_{1 / 2} \text { (vs SCE) [V] }+0.475 & -0.070 & -0.01 & -0.13
\end{array} \\
& \begin{array}{llll}
\mathrm{Cp}_{2} \mathrm{TiCl}_{2} & \left(\mathrm{Me}_{5} \mathrm{Cp}\right)_{2} \mathrm{TiCl}_{2} & \left(c \mathrm{Pr}_{4} \mathrm{CpH}\right)_{2} \mathrm{TiCl}_{2} & \left(c \mathrm{Pr}_{5} \mathrm{Cp}\right)_{2} \mathrm{TiCl}_{2} \\
\hline
\end{array} \\
& E_{1 / 2} \text { (vs SCE) [V] }-0.90 \quad-1.08 \quad-1.21
\end{aligned}
$$

Fig. 6 Oxidation potentials of some metallocenes as a probe for ligand properties [28].

It is evident that 10 cyclopropyl groups are more efficient than only 8 in lowering the oxidation potential of the corresponding ferrocene, and they do so by a larger margin than 10 methyl substituents. However, the electron demand of the iron nucleus apparently is not as large as that of a dichlorotitanium moiety in the corresponding titanocene dichlorides, as evidenced by the significant drop in the oxidation potential on going from decamethyltitanocene dichloride to the octacyclopropyl analog. It will be interesting to see the value for the decacyclopropyltitanocene dichloride as well, but it has not yet been prepared.

Trapping experiments have shown that the pentacyclopropylcyclopentadienyl cation, when generated under solvolytic conditions, survives at least for short times at $0{ }^{\circ} \mathrm{C}$. When the cyclopentadienyl chloride precursor was treated with silver tetrafluoroborate in pentane/methylene chloride solution in the presence of methanol, the pentacyclopropylcyclopentadienyl methyl ether with all five cyclopropyl groups intact was isolated in $75 \%$ yield after workup with potassium carbonate [29].

Ring opening of one cyclopropyl group does, however, occur when the chloride precursor is subjected to chromatography on silica gel, eluting with pentane. This originally attempted purification of the cation precursor gave 1,2,3,4-tetracyclopropyl-(6-chloroethyl)fulvene as orange crystals in $48 \%$ yield. This fulvene, in addition to NMR spectroscopy, was characterized by its UV spectrum as well as its Diels-Alder adduct with dimethyl acetylenedicarboxylate (Scheme 5). In contrast to the chloride, the pentacyclopropylcyclopentadienyl methyl ether is stable in moist air for extended times. This same ether is also obtained in $40 \%$ yield upon quenching the solution prepared by treatment of the chloride precursor with 10 equiv of antimony pentafluoride in $\mathrm{SO}_{2} \mathrm{ClF} / \mathrm{SO}_{2} \mathrm{~F}_{2}$ solution at $-115{ }^{\circ} \mathrm{C}$ with methanol. The cationic intermediate leading to this methyl ether has not yet been unequivocally identified by NMR spectroscopy, but preliminary results do look promising [29]. Indeed, the pentacyclopropylcyclopentadienyl cation ought to have a good chance to be identified since, according to DFT cal- 


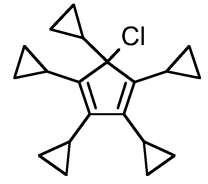

\begin{tabular}{l|l}
$\mathrm{SiO}_{2}$, & $48 \%$
\end{tabular}<smiles>ClCCC=C1C(C2CC2)=C(C2CC2)C(C2CC2)=C1C1CC1</smiles>

orange crystals
1) $\mathrm{AgBF}_{4}$, pentane $/ \mathrm{CH}_{2} \mathrm{Cl}_{2} /$ $\mathrm{MeOH}, 5 \mathrm{~min}$

$-78 \rightarrow 0{ }^{\circ} \mathrm{C}$

$75 \%$

$\mathrm{PhCl}, \Delta, 18 \mathrm{~h}$

$61 \%$

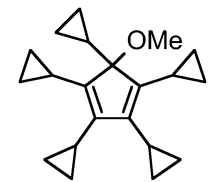

stable in moist air

Scheme 5 Trapping of the pentacyclopropylcyclopentadienyl cation under solvolytic conditions.

culations at the B3LYP/6-31G* level using isodesmic equations, as a singlet it is more stable than the singlet pentamethylcyclopentadienyl cation by $29.3 \mathrm{kcal} / \mathrm{mol}$, and also more stable than the singlet pentaisopropylcyclopentadienyl cation by $19.4 \mathrm{kcal} / \mathrm{mol}$ (Scheme 6) [23].
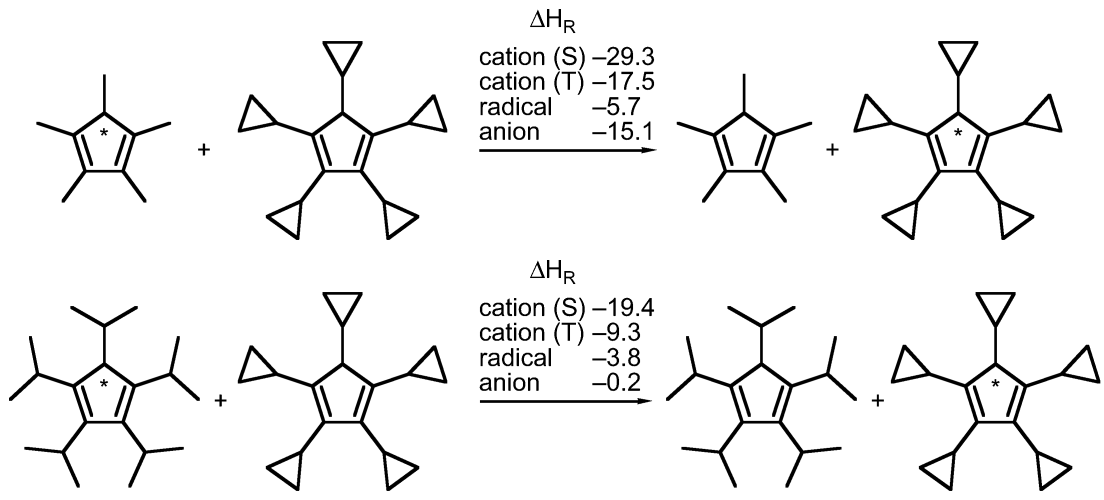

Scheme 6 Isodesmic stabilization energies (in $\mathrm{kcal} / \mathrm{mol}$ ) of pentasubstituted cyclopentadienyl species (all structures fully optimized at the B3LYP/6-31G* level) [23].

An attempted hydride abstraction with trityl tetrakis(pentafluorophenyl)borate in methylene chloride solution at -78 to $-50{ }^{\circ} \mathrm{C}$ or with trityl tetrafluoroborate at room temperature only led to the pentacyclopropylcyclopentenyl cation as its single trans-isomer, just as was observed in the attempted generation of pentamethylcyclopentadienyl cation by hydride abstraction from pentamethylcyclopentadiene [21]. The rather stable pentacyclopropylcyclopentenyl cation is more efficiently generated by protonation of the hydrocarbon with tetrafluoroboric acid in methylene chloride at $20^{\circ} \mathrm{C}$. This conversion proceeded cleanly yielding a 4:1 mixture of the trans- and cis-isomers quantitatively (Scheme 7) [29].
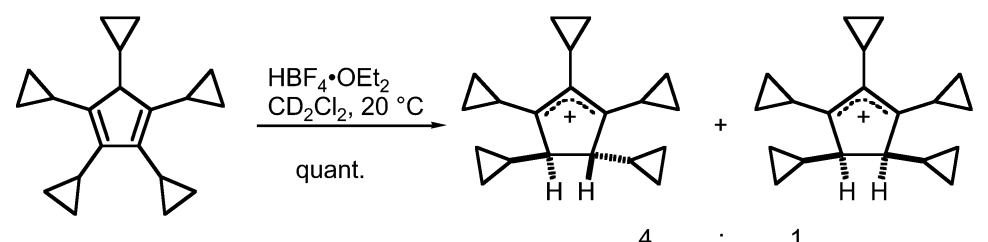

Scheme 7 Protonation of pentacyclopropylcyclopentadiene to yield the trans- and cis-pentacyclopropylcyclopentenyl cations [29]. 
The protonation of fulvenes is known not to occur at the exocyclic methylene group to give cyclopentadienyl cations, but at one of the double bonds of the cyclopentadiene moiety to yield fulvenyl cations [30]. The previously unknown 1,2,3,4-tetracyclopropylfulvene was obtained by condensation of lithium tetracyclopropylcyclopentadienide with formaldehyde, and the structurally even more interesting 6,6-ethano-1,2,3,4-tetracyclopropylfulvene (5-cyclo-propylidene-1,2,3,4-tetracyclopropylcyclopentadiene) by hydride abstraction with trityl tetrafluoroborate from lithium pentacyclopropylcyclopentadienide. While protonation of tetracyclopropylfulvene led to a fulvenyl cation which decomposed above $-60{ }^{\circ} \mathrm{C}$, the analogous cation obtained from the 6,6-ethano-bridged derivative was completely stable at $-50{ }^{\circ} \mathrm{C}$ for extended times and could be fully characterized by ${ }^{1} \mathrm{H}$ - and ${ }^{13} \mathrm{C}$ NMR spectroscopy (Scheme 8) [29].
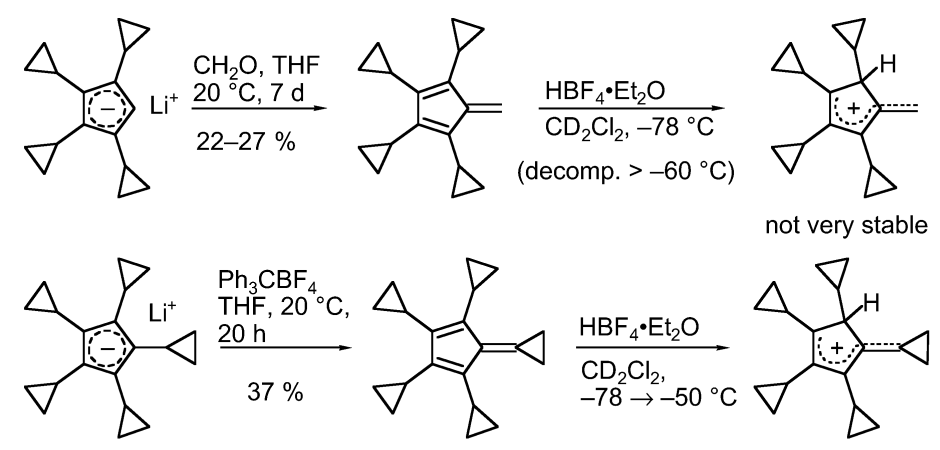

orange crystals, m. p. $43^{\circ} \mathrm{C}$
$\lambda_{\max }=391 \mathrm{~nm}$ in $\mathrm{MeCN}(\lg \varepsilon=4.16)$

completely stable at $-50{ }^{\circ} \mathrm{C}$

${ }^{1} \mathrm{H},{ }^{13} \mathrm{C}$ NMR

Scheme 8 New oligocyclopropyl-substituted fulvenes and fulvenyl cations.

\section{TRICYCLOPROPYLAMINE RADICAL CATIONS}

With this cation-stabilizing effect in mind, tricyclopropylamine was expected to form a more stable radical cation than triisopropylamine which, in 1991, had been reported to undergo oxidation at a surprisingly low potential to a persistent radical cation (Scheme 9) [31]. At that time, tricyclopropylamine was unknown, and it was not taken into account that three isopropyl groups have a larger planarizing effect on the central nitrogen than three smaller cyclopropyl groups [32].

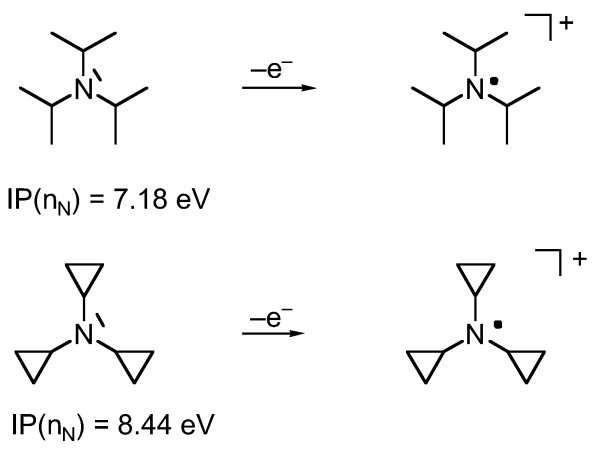

Scheme 9 Triisopropylamine [33] vs. tricyclopropylamine and their radical cations.

In order to test this hypothesis, a synthesis of tricyclopropylamine starting from benzylcyclopropylformamide was designed and successfully executed [33] on the basis of the titanium-mediated re- 
ductive cyclopropanation previously developed by us [34]. Surprisingly at first sight, the ionization potential of tricyclopropylamine turned out to be $1.26 \mathrm{eV}$ higher than that of triisopropylamine (8.44 vs. $7.18 \mathrm{eV})$. The reason for that became evident by X-ray crystal and electron diffraction gas-phase structure analyses. Both in the crystal and in the gas phase, tricyclopropylamine is not only pyramidal at nitrogen, but adopts an orientation of all three cyclopropyl groups, which does not allow for electron donation into the developing semi-occupied orbital on the central atom (Fig. 7).
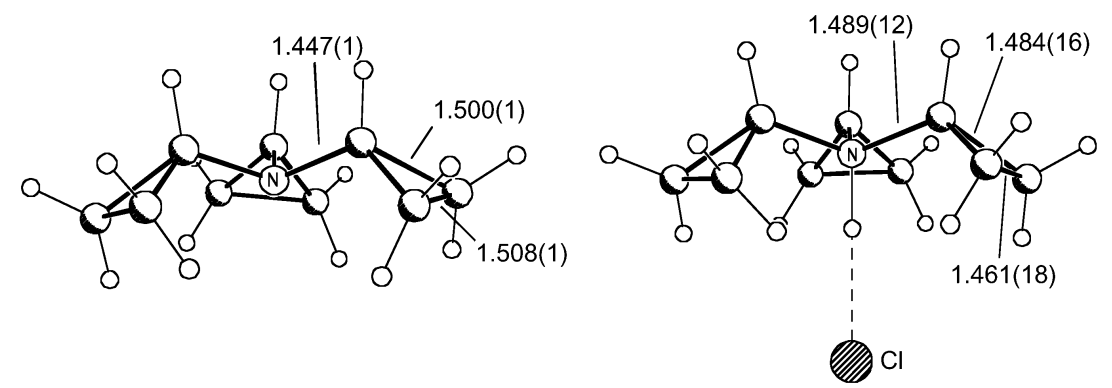

Fig. 7 Structure of tricyclopropylamine in the crystal and in the gas phase as well as tricyclopropylamine hydrochloride in the crystal. Distances in $\AA$ [33].

Even the hydrochloride with its protonated nitrogen has the same orientation of all three cyclopropyl groups [33].

While it proved impossible to generate the radical cation from tricyclopropylamine by chemical oxidation in solution, it eventually could be identified by electron paramagnetic resonance (EPR) spectroscopy after cobalt $\gamma$-irradiation of a freon matrix at $-196{ }^{\circ} \mathrm{C}$. The unique feature was that an isotropic spectrum could only be observed upon warming the matrix to a temperature of $-148{ }^{\circ} \mathrm{C}$, which is very close to its softening point.

This was taken as an evidence that a major conformational change has to occur on going from the neutral amine to the radical cation, and this can only happen when the matrix is soft enough. In fact, according to calculations (Fig. 8), the tricyclopropylamine radical cation is completely planar at nitrogen with the three cyclopropyl groups in a perfectly bisected orientation with respect to the axis of the semioccupied orbital on nitrogen. Thus, all three cyclopropyl groups around nitrogen in the neutral have to undergo internal rotation by $90^{\circ}$ while nitrogen is flattening upon single electron removal [35].

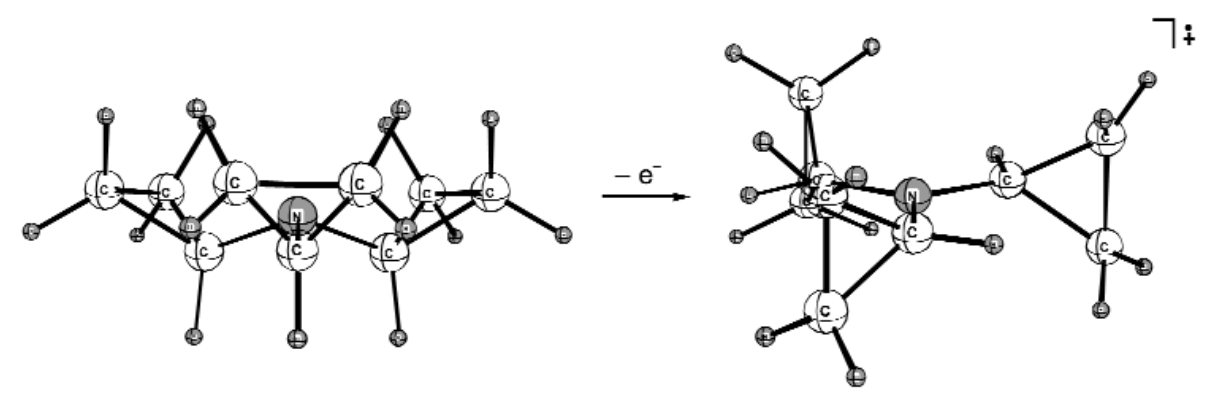

Fig. 8 Tricyclopropylamine and its radical cation according to RB3LYP/6-31G(d), UB3LYP/6-31G(d) computations [33]. 


\section{CONFORMATIONAL DYNAMICS IN TETRACYCLOPROPYL- AND TETRAISOPROPYLMETHANE}

Exactly the same behavior would be predicted for tricyclopropylmethane and its transformation to the tricyclopropylmethyl cation. Indeed, a crystal structure analysis revealed that tricyclopropylmethane has $C_{3 \mathrm{v}}$ symmetry in the solid [36], and undoubtedly tricyclopropylmethyl cation would have a trigonal planar coordination around the central carbon with all three cyclopropyl groups in a bisected orientation [15].

However, the orientation of the three cyclopropyl groups in tricyclopropylmethane cannot be maintained, when a fourth cyclopropyl group is attached to the central carbon. Tetracyclopropylmethane, however, had not been reported before, and thus a synthesis had to be designed. Starting from ethyl 3,3-dicyclopropylacrylate, tetracyclopropylmethane was eventually prepared in six steps with an overall yield of $23 \%$. In the crystal, the molecule does indeed adopt an $S_{4}$ symmetric shape (Fig. 9) [36].
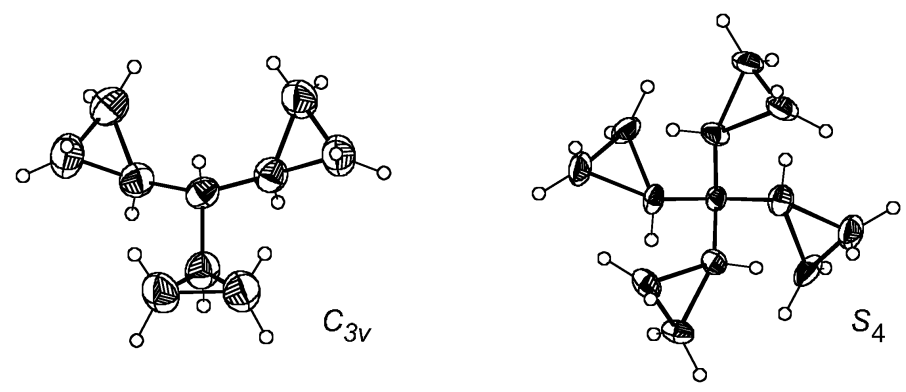

Fig. 9 Structures of tricyclopropylmethane and tetracyclopropylmethane in the crystals [36].

The interesting dynamic behavior of this molecule was eventually disclosed by ${ }^{13} \mathrm{C}$ NMR spectra taken at -165 and $-180{ }^{\circ} \mathrm{C}$ [37].

The conformational changes, which are slowed down at $-165{ }^{\circ} \mathrm{C}$, convert states $\mathrm{T} 3{ }^{1}$ via $\mathrm{T} 6^{2}$ and $\mathrm{T}^{3}{ }^{3}$ into $\mathrm{T}^{3}$ and alike. This occurs, as derived from a complete line-shape analysis, with a free energy of activation of $4.5 \mathrm{kcal} / \mathrm{mol}$ (Fig. 10). Tetracyclopropylmethane also served as a precursor to the even
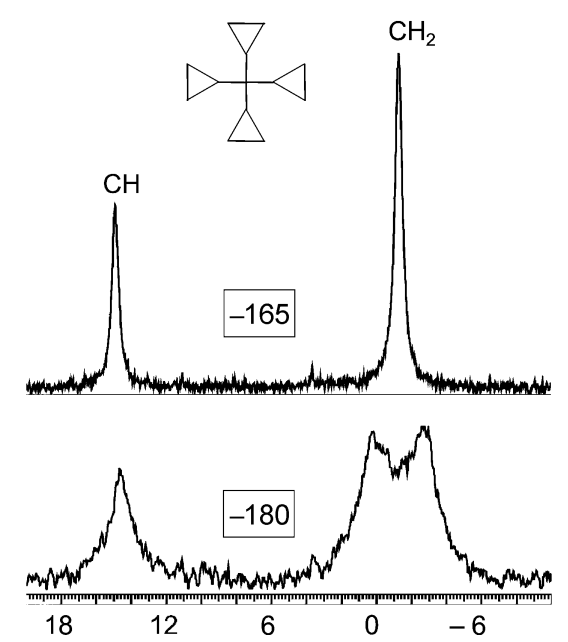
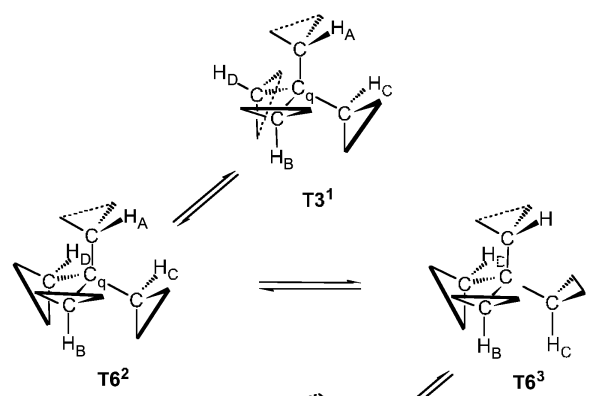

$\Delta \mathrm{G}^{\neq}=4.5 \mathrm{kcal} / \mathrm{mol}$

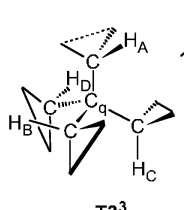

$\mathrm{T}^{3}$

Fig. $10{ }^{13} \mathrm{C}$ NMR spectra of tetracyclopropylmethane at -165 and $-180{ }^{\circ} \mathrm{C}$ in $\mathrm{CHF}_{2} \mathrm{Cl} / \mathrm{CHFCl}_{2}$ (4:1, v/v ratio) solution [37]. 
more highly crowded tetraisopropylmethane. Catalytic hydrogenation of tetracyclopropylmethane over platinum oxide in acetic acid occurred remarkably smoothly and selectively with a quantitative yield of tetraisopropylmethane [36].

In the crystal, tetraisopropylmethane has $C_{2 \mathrm{v}}$ symmetry with two pairs of isopropyl groups facing each other (Fig. 11). The dynamics of this molecule was revealed by studying the temperature dependence of its ${ }^{1} \mathrm{H}$ NMR spectrum down to $-115{ }^{\circ} \mathrm{C}$. A minor conformer was clearly detected at this low temperature with a proportion of $6.5 \%$, and a complete line-shape analysis revealed a free-energy barrier to conformational changes in this molecule of $9.7 \mathrm{kcal} / \mathrm{mol}$ [37].
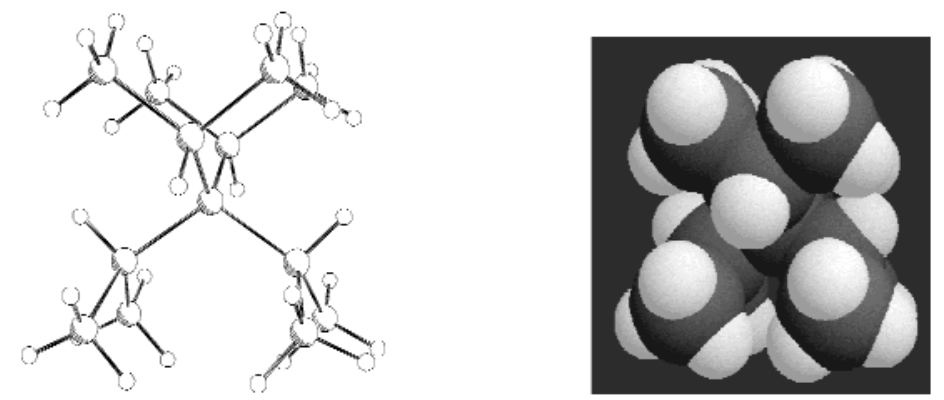

Fig. 11 Structure of tetraisopropylmethane, an overcrowded molecule in the crystal [36].

\section{ACKNOWLEDGMENTS}

The senior author (AdM) is grateful to a group of dedicated young coworkers who have produced all of the presented experimental results. He is indebted to Profs. Fabian Gerson, Basel (EPR spectroscopy), Thomas Bally, Fribourg (cobalt $\gamma$-irradiation), Rolf Gleiter, Heidelberg, and Paul Rademacher, Essen (photoelectron spectra), Roland Boese, Essen, Jörg Magull, Göttingen, Dmitri S. Yufit, Durham (X-ray crystallography), Burkhard König, Regensburg (cyclovoltammetry), Hans-Ulrich Siehl, Ulm (cation generation), J. Edgar Anderson, London, and Ludovico Lunazzi, Bologna (conformational analysis) for fruitful collaborations. Financial support from the Fonds der Chemischen Industrie, Studienstiftung des deutschen Volkes, Deutscher Akademischer Austauschdienst, Alexander von Humboldt-Stiftung and Gottlieb-Daimler und Karl-Benz-Stiftung is gratefully acknowledged.

\section{REFERENCES AND NOTES}

1. W. H. Perkin. Ber. Deutsch. Chem. Ges. 17, 54-59 (1884).

2. A. de Meijere. Chem. Uns. Zeit 16, 13-22 (1982) and references cited therein.

3. (a) Reviews: J. Salaün. Top. Curr. Chem. 207, 2-67 (2000); (b) J. Salaün, M. S. Baird. Curr. Med. Chem. 2, 511-542 (1995); (c) For recent results in this area, see also: A. G. M. Barrett, D. Hamprecht, R. A. James, M. Ohkubo, P. Procopiou, M. A. Toledo, A. J. P. White, D. J. Williams. J. Org. Chem. 66, 2187-2196 (2001) and references cited therein.

4. N. S. Zefirov, S. I. Kozhushkov, T. S. Kuznetsova, O. V. Kokoreva, K. A. Lukin, B. I. Ugrak, S. S. Tratch. J. Am. Chem. Soc. 112, 7702-7707 (1990).

5. For a recent review, see: A. de Meijere and S. I. Kozhushkov. Chem. Rev. 100, 93-142 (2000).

6. Originally, the term "cryptochiral" had been suggested for such compounds. See: K. Mislow and P. Bickart. Isr. J. Chem. 15, 1 (1976/1977). In considering what "cryptochiral" is to describe, one has to point out a serious deficiency, as any racemate might also be called cryptochiral. "Cryptooptically active" appears to be a more appropriate term.

7. A. de Meijere, A. F. Khlebnikov, R. R. Kostikov, S. I. Kozhushkov, P. R. Schreiner, A. Wittkopp, D. S. Yufit. Angew. Chem. 111, 3682-3685 (1999); Angew. Chem., Int. Ed. 38, 3474-3477 (1999). 
8. A. de Meijere, A. F. Khlebnikov, S. I. Kozhushkov, R. R. Kostikov, P. R. Schreiner, A. Wittkopp, C. Rinderspacher, H. Menzel, D. S. Yufit, J. A. K. Howard. Chem. Eur. J. 8, 828-842 (2002).

9. The stereochemical features of unbranched triangulanes have been thoroughly analyzed: see ref. 4.

10. A. F. Khlebnikov, S. I. Kozhushkov, D. S. Yufit, J. A. K. Howard, D. Frank, K. Miyazawa, A. de Meijere. Unpublished results. Cf. Kiyazawa, Dissertation, Universität Göttingen 1999; Novel Liquid Crystalline Compounds with Cyclopropane Rings: Syntheses and Properties, Cuvillier, Göttingen (2001).

11. (a) J. M. Denis, P. Le Perchec, J.-M. Conia. Tetrahedron 33, 399-408 (1977); (b) Review: K. A. Lukin and N. S. Zefirov. In The Chemistry of the Cyclopropyl Group, Z. Rappoport (Ed.), Vol. 2, pp. 861-885, Wiley, New York (1995).

12. The DFT-calculated vertical ionization energies agree perfectly with the experimentally determined (by Photoelectron Spectroscopy) values. R. Gleiter, R. Haider, J.-M. Conia, J.-P. Barnier, A. de Meijere, W. Weber, J. Chem. Soc., Chem. Commun. 1979, 130-132.

13. A. A. Fokin, P. R. Schreiner, S. I. Kozhushkov, K. Sattelmeyer, H. F. Schaefer, A. de Meijere. Org. Lett. 5, 697-700 (2003).

14. A. A. Fokin, P. R. Schreiner, S. I. Kozhushkov, H. Schill, T. Bally, F. Gerson, R. Boese, A. de Meijere. Unpublished results.

15. (a) Reviews: A. de Meijere. Angew. Chem. 91, 867-884 (1979); Angew. Chem., Int. Ed. Engl. 18, 809-826 (1979); (b) K. B. Wiberg. In Methods of Organic Chemistry, (Houben-Weyl), Vol. E17a, A. de Meijere (Ed.), pp. 1-27, Thieme, Stuttgart (1997); (c) T. T. Tidwell. In The Chemistry of the Cyclopropyl Group, Z. Rappoport (Ed.), pp. 565-632, Wiley, Chichester (1987).

16. (a) K. Komatsu, I. Tomioka, K. Okamoto. Tetrahedron Lett. 21, 947-950 (1980); (b) R. A. Moss and R. C. Munjal. Tetrahedron Lett. 21, 1221-1222 (1980); (c) T. Kitagawa, T. Tanaka, H. Murakita, K. Takeuchi. J. Org. Chem. 64, 2-3 (1999) and references cited therein; (d) X-ray crystal structure: R. A. Moss, S. Shen, K. Krogh-Jespersen, J. A. Potenza, H. J. Schugar, R. C. Munjal. J. Am. Chem. Soc. 108, 134-140 (1986).

17. (a) K. Komatsu, K. Takeuchi, M. Arima, Y. Waki, S. Shirai, K. Okamoto. Bull. Soc. Chem. Jpn. 55, 3257-3261 (1982); (b) K. Okamoto, T. Kitagawa, T. Takeuchi, K. Ken'ichi, K. Komatsu, T. Kinoshita, S. Aonuma, M. Nagai, A. Miyabo. J. Org. Chem. 55, 996-1002 (1990).

18. (a) M. Saunders, R. Breslow, E. Wasserman. J. Am. Chem. Soc. 95, 3017-3018 (1973); (b) R. Breslow and S. Mazur. J. Am. Chem. Soc. 95, 584-585 (1973); (c) G. B. I. Scott, D. B. Milligan, D. A. Fairley, C. G. Freeman, M. J. McEwan. J. Chem. Phys. 112, 4959-4965 (2000) and references cited therein.

19. (a) R. Breslow, R. Hill, E. Wasserman. J. Am. Chem. Soc. 86, 5349-5350 (1964); (b) H. Vancik, I. Novak, D. Kidemet. J. Phys. Chem. A 101, 1523-1525 (1997).

20. H. Sitzmann, H. Bock, R. Boese, T. Dezember, Z. Havlas, W. Kaim, M. Moscherosch, L. Zanathy. J. Am. Chem. Soc. 115, 12003-12009 (1993).

21. For a discussion on the pentamethylcyclopentadienyl cation, see: (a) M. Otto, D. Scheschkewitz, T. Kato, M. M. Midland, J. B. Lambert, G. Bertrand. Angew. Chem. 114, 2379-2380 (2002); Angew. Chem., Int. Ed. 41, 2275-2276 (2002); (b) T. Müller. Angew. Chem. 114, 2380-2382 (2002); Angew. Chem., Int. Ed. 41, 2276-2278 (2002); (c) J. B. Lambert. Angew. Chem. 114, 2383 (2002); Angew. Chem., Int. Ed. 41, 2279 (2002); (d) J. B. Lambert, L. Lin, V. Rassolov. Angew. Chem. 114, 1487-1489 (2002); Angew. Chem., Int. Ed. 41, 1429-1431 (2002).

22. (a) R. Breslow, H. W. Shang, W. A. Yager. J. Am. Chem. Soc. 85, 2033-2034 (1963); (b) W. Broser, H. Kurreck, P. Siegle. Chem. Ber. 100, 788-794 (1967); (c) W. Broser, P. Siegle, H. Kurreck. Chem. Ber. 101, 69-83 (1968); (d) R. Breslow and S. Mazur. J. Am. Chem. Soc. 95, 584-585 (1973). 
23. (a) P. R. Schreiner, I. Emme, A. de Meijere. Unpublished results; (b) For calculations of NMR data of open-shell systems see: V. Gogonea, P. v. R. Schleyer and P. R. Schreiner. Angew. Chem. 110, 2045-2049 (1998); Angew. Chem., Int. Ed. Engl. 37, 1945-1948 (1998).

24. Large positive values are characteristic for antiaromatic, negative NICS values for aromatic systems: (a) P. v. R. Schleyer, C. Maerker, A. Dransfeld, H. Jiao, N. J. R. v. E. Hommes. J. Am. Chem. Soc. 118, 6317-6318 (1996); (b) P. v. R. Schleyer, P. K. Freeman, H. Jiao, B. Goldfuß. Angew. Chem. 107, 332-335 (1995); Angew. Chem., Int. Ed. Engl. 34, 337-340 (1995).

25. H.-C. Militzer, S. Schömenauer, C. Otte, C. Puls, J. Hain, S. Bräse, A. de Meijere. Synthesis 1993, 998-1012 and references cited therein.

26. (a) F. Sato, H. Tshikawa, M. Sato. Tetrahedron Lett. 22, 85-88 (1981); (b) F. Sato and Y. Kobayashi. Org. Synth. 69, 106-113 (1990).

27. Adapted from a procedure for the selective 1,2-addition of organomagnesium derivatives to $\alpha, \beta$-unsaturated ketones according to: T. Imamoto, N. Takiyama, K. Nakamura. Tetrahedron Lett. 26, 4763-4766 (1985).

28. I. Emme, S. Redlich, T. Labahn, J. Magull, A. de Meijere. Angew. Chem. 114, 811-814 (2002); Angew. Chem., Int. Ed. 41, 786-789 (2002).

29. S. Redlich, I. Emme, Chr. Freudenberger, H.-U. Siehl, A. de Meijere. Unpublished results.

30. G. A. Olah, G. K. Surya Prakash, G. Liang. J. Org. Chem. 42, 661-666 (1977).

31. H. Bock, I. Goebel, Z. Havlas, S. Liedle, H. Oberhammer. Angew. Chem. 103, 193-196 (1991); Angew. Chem., Int. Ed. Engl. 30, 187-190 (1991).

32. In fact, according to a gas phase electron diffraction structure analysis, triisopropylamine was interpreted to be planar at nitrogen. However, an X-ray crystal structure analysis of triisopropylamine disclosed that this molecule deviates from planarity around nitrogen by $11^{\circ}$ : R. Boese, D. Blaeser, M. Y. Antipin, V. Chaplinski, A. de Meijere. Chem. Commun. 781-782 (1998).

33. (a) A. de Meijere, V. Chaplinski, H. Winsel, M. A. Kuznetsov, P. Rademacher, R. Boese, T. Haumann, M. Traetteberg, P. v. R. Schleyer, T. Zywietz, H. Jiao, P. Merstetter, F. Gerson. Angew. Chem. 111, 2582-2585 (1999); Angew. Chem., Int. Ed. 38, 2430-2433 (1999); (b) For an alternative preparation of tricyclopropylamine, see: M. L. Gillaspy, B. A. Lefker, W. A. Hada, D. J. Hoover. Tetrahedron Lett. 36, 7399-7402 (1995).

34. (a) V. Chaplinski and A. de Meijere. Angew. Chem. 108, 491-492 (1996); Angew. Chem., Int. Ed. Engl. 35, 413-414 (1996); (b) V. Chaplinski, H. Winsel, M. Kordes, A. de Meijere. Synlett 111-114 (1997) .

35. A. de Meijere, V. Chaplinski, F. Gerson, P. Merstetter, E. Haselbach. J. Org. Chem. 64, 6951-6959 (1999).

36. S. I. Kozhushkov, R. R. Kostikov, A. P. Molchanov, R. Boese, J. Benet-Buchholz, P. R. Schreiner, C. Rinderspacher, I. Ghiviriga, A. de Meijere. Angew. Chem. 113, 179-182 (2001); Angew. Chem., Int. Ed. 40, 180-183 (2001).

37. J. E. Anderson, A. de Meijere, S. I. Kozhushkov, L. Lunazzi, A. Mazzanti. J. Am. Chem. Soc. 124, 6706-6713 (2002). 